ISSN 0103-5150

Fisioter. Mov., Curitiba, v. 28, n. 2, p. 307-317, Apr./June 2015

Licenciado sob uma Licença Creative Commons DOI: http://dx.doi.org.10.1590/0103-5150.028.002.A011

\title{
Physiotherapy and patients with osteogenesis imperfecta: an experience report
}

\author{
Fisioterapia e pacientes com osteogênese \\ imperfeita: história de uma experiência
}

\section{Carmem Lia Martins Moreira, Ana Cristina Bohrer Gilbert, Maria Angélica de Faria Domingues Lima, Maria Helena Cabral de Almeida Cardoso, Juan Clinton Llerena Jr**}

Fundação Oswaldo Cruz (Fiocruz), Instituto Nacional de Saúde da Mulher, da Criança e do Adolescente Fernandes Figueira (IFF), Rio de Janeiro, RJ, Brazil

\begin{abstract}
Introduction: Individuals with osteogenesis imperfecta (OI) have bone fragility and osteopenia which cause fractures, mobility restriction and pain. Objective: This article examines a physiotherapy experience with people diagnosed with OI in an OI reference center of Rio de Janeiro. Materials and methods: This was an exploratory qualitative study, based on field notes related to physiotherapy care to 92 patients of both genders with clinical diagnoses of OI, aged between 30 days and 37 years old, during the period 2004-2008. The analysis comprised a reading of the field notes as a corpus, considering them as a means of understanding the
\end{abstract}

* CLMM: PhD, e-mail: c.lia9@globo.com ACBG: PhD, e-mail: ana.cbgilbert@yahoo.com MAFDL: MSc, e-mail: mangelicafdl@gmail.com MHCAC: PhD, e-mail: cardosomhca@iff.fiocruz.br JCLJ: PhD, e-mail: llerena@iff.fiocruz.br 
subjects' perspectives. Two different forms of codification were applied - open and focused - followed by semiotic analysis techniques. Results: Early encouragement to perform active movements within a safe environment, or even after fractures, reduced articular contractures and enhanced muscular tonus; physiotherapy manipulation facilitated the integration of body perception in relation to movements and responses to tactilekinesthetic-vestibular stimuli; promoting family involvement, by adopting practical solutions adapted to each patient's reality, contributed to reduce fear of fractures and allowed the construction of a new functional image. Conclusion: Physiotherapy assessment and treatment should be based not only on clinical and neurofunctional elements and technical strategies, but also on a dialogue that includes the multiple dimensions of the patients and their family members, in order to engage them in a learning process to stimulate potentials, abilities and competences.

Keywords: Physiotherapy. Osteogenesis imperfecta. Qualitative research. Case studies.

\section{Resumo}

Introdução: Os indivíduos com osteogênese imperfeita (OI) sofrem de grande fragilidade óssea e osteopenia, que ocasionam inúmeras fraturas, restrição da mobilidade e dor. Objetivo: Expor pacientes com diagnóstico de OI à experiência do tratamento fisioterapêutico levado a cabo em centro de referência em Osteogênese Imperfeita do Rio de Janeiro. Materiais e métodos: Estudo qualitativo, exploratório, baseado em notas de campo relativas à assistência fisioterapêutica a 92 pacientes com diagnóstico clínico de OI, com idade variando entre 30 dias e 37 anos, de ambos os sexos, atendidos entre 2004 e 2008. A análise compreendeu a leitura das anotações enquanto um corpus, considerando todo o registro da experiência de campo tal como ela se desenvolveu, empreendendo-se uma codificação aberta e uma enfocada, seguidas da aplicação de técnicas semióticas. Resultados: 0 incentivo precoce aos movimentos ativos em ambiente seguro ou mesmo após as fraturas reduziu contraturas articulares e melhorou o tônus muscular; os manuseios fisioterapêuticos empregados facilitaram a integração da percepção do corpo quanto à ação dos movimentos e às respostas aos estímulos táteis, cinestésicos e vestibulares; a promoção do envolvimento familiar, via adoção de soluções práticas adaptadas à realidade de cada paciente, ajudou no afastamento do medo às fraturas e permitiu a construção de uma nova imagem corporal. Conclusão: Para além da técnica, dos componentes clínicos e neurofuncionais, a ação fisioterapêutica deve se assentar num diálogo que permita abranger as múltiplas dimensões dos pacientes e seus familiares, no sentido de engajá-los em um processo de aprendizagem agenciador de potencialidades, competências e habilidades.

Palavras-chave: Fisioterapia. Osteogênese imperfeita. Pesquisa qualitativa. Estudos de casos.

\section{Introduction}

Osteogenesis imperfecta (OI) is a genetically determined condition characterized by extreme bone fragility and osteopenia. It affects approximately 1:5000-10000 individuals (1). It is a rare and potentially disabling disease, the clinical heterogeneity of which is so striking that the initial classification comprised four groups (2) with a further four added $(3,4,5,6,7)$, however, inconsistencies concerning the characteristics and prognosis of each type still remain (8).

Physiotherapy has played an important role in the motor development and motor and functional rehabilitation of patients with OI in recent years in Brazil. Regulation No. 2305/2001 of the Ministry of Health approved the OI Clinical Treatment Indication Protocol with the medication pamidronate disodium (PD) within the Brazilian National Health System (SUS) and also created the OI Reference Centers (OIRCs) (9). The Fernandes Figueira National Institute of Woman, Child and Adolescent Health (INSMCA/IFF/Fiocruz), mother and child unit of the Oswaldo Cruz Foundation (Fiocruz) has been accredited as OIRC/IFF and general coordinator of the other OIRC participants in Brazil. Since April 2002, the Physiotherapy Program of CROI/IFF has offered physiotherapy monitoring for these patients, 
developing specific treatment and providing guidance to their family members.

The few reports found in the literature on the importance of physiotherapy in the treatment of OI, contain little specific guidance. No articles were found that mention which manipulations are effective and recommended, finding only references regarding the need to start the stimuli early. In general, the studies only suggest a program of exercises and positions that will help with the development of muscle strength and conditioning, while maintaining or increasing the range of joint motion, in order to promote bone mineralization through load support promoted by orthostatism (10); others consider the use of orthoses or adaptive equipment in order to assist the motor development $(11,12)$, as well as advise early mobilization to prevent worsening of bone fragility and muscular weakness. However, they do not provide enough information to guide a clinical approach supported by experience acquired by physiotherapists.

Faced with the limited scientific literature, we sought to listen to and contemplate the reports and complaints of the patients and/or their families, in order to comprehend the difficulties they encounter in their routines and to achieve the necessary care imposed by this disease.

Accordingly, with regard to the difficulties related to the motor development and rehabilitation, we focus our work on the explanation and discussion of the postural transitions and variability of movements that give rise to the significant reduction of: (a) defense reaction to contacts, (b) tendency for postural fixations, (c) fear of moving, and (d) soft tissues restrictions, consequently resulting in improvements in the development of body and space perception, and the interactions of the patient with him/herself and the surroundings.

For this, we also employ guidance for the parents, the purpose of which is to try to find responses to the requirements of each patient, taking into consideration the age group and the clinical and social conditions. Through the reports of family members we are able to comprehend doubts regarding the performance of routine activities and care, feelings of insecurity, fear of failure to provide the protection that this condition requires, transcending the purely clinical/physiological aspect and thus facilitating a more efficient form of communication, leading to the strengthening of the bonds among the family members and with the physiotherapist.
Given the above, it becomes very clear that our observations and questions are linked to the proposals of the World Health Organization (WHO), through the International Classification of Functioning, Disability and Health (ICF), as this recognizes the importance of knowledge of diseases according to the functionality, disability and disadvantages related to health conditions and thus expands the areas of practice for health professionals in the knowledge of individuals in relation to their daily lives (13).

In short, this article, linked to physiotherapy performed at CROI/IFF as a public health action, aims to contribute to a deeper comprehension of the human movement in this disease, including the physical, functional and personal repercussions, as well as to provide a foundation for future clinical decisions in order to consolidate conditions for a full life for patients with IO in Brazil.

\section{Materials and methods}

This was a qualitative, exploratory study, based on field notes related to the physiotherapeutic care performed in the Motor Physiotherapy Outpatient Clinic of INSMCA/IFF/Fiocruz for patients with clinical diagnoses of IO, attended by CROI/IFF between 2004 and 2008, comprising a case study (14). These field notes refer to 92 patients with confirmed diagnoses of IO based on the clinical and laboratory criteria used in this reference center, comprising: bone fragility characterized by recurrent fractures; positive family history of IO; blue sclera; early deafness; short stature; dentinogenesis imperfecta; radiographic alterations consistent with IO and osteoporosis assessed through bone densitometry. The ages of the patients ranged from one month to 37 years old.

The notes were written after the first consultations and monitoring, mainly encompassing the description of the physiotherapeutic practices and strategies, family experience with the disease, the opinion of the family members and the patients themselves with regard to gains or in the case of little or no noted improvement, and the recommendations of intervention activities to be reproduced within the family context.

The analysis included the reading of the notes as a corpus, considering the entire record of the field experience as it was developed. We undertook an open and focused encoding, followed by the application 
of adapted semiotic techniques of Cardoso (15). We emphasize that we chose to present the results and discussion as a single item, as the separation of them would result in a fragmented exhibition of the history of the experience, the object of our study.

The research project was submitted to the Research Ethics Committee of INSMCA/IFF/Fiocruz and approved under authorization No. CAAE0075.0.008.000-10. Permission to use the images was given by the parents or guardians through informed consent, without any opposition to the facial registration of the children or those responsible.

\section{Results and discussion}

The use of PD in the treatment of IO is still regarded as a recent clinical investment in our country, which required a period of therapeutic developments and attentive observations during physiotherapy that would allow us to evaluate and thoroughly describe the needs of the patients and their family members, as well as obtain sufficient clinical parameters to characterize an effective improvement offered by the Physiotherapy Program of CROI/IFF.

Motility involves the body of the subject in an interaction with the environment and is capable of inducing tactile-kinesthetic, vestibular and proprioceptive sensations $(16,17,18)$.

Given this perspective, we contextualize the ways to expand the possibilities of the physiotherapy aimed at individuals with IO, considering the tactile stimuli and preventive actions as well as the clinical assumptions and knowledge regarding the role of physiotherapy, including them as instruments to fulfill the various therapeutic needs and postulate a preventive clinical attitude.

The implication of fractures in clinical physiotherapy goes beyond simple temporary immobility, being responsible for the worsening of hypotonia, frequently present in many of the patients treated at CROI/IFF, and the discontinuity of the physiotherapeutic treatment. These episodes reinforce the fear of bone fragility, often impeding the performance of tasks by individuals with IO or their movement by family members. This is most evident in young children where the mothers handle their children very little, depriving them of appropriate tactilekinesthetic perceptions, which promote interaction and tactile comfort $(18,19,20)$. Furthermore, the presence of pain is a major impediment to all types of care, constituting a barrier to the proximity of the mother and health professionals.

The recovery from fractures and the effects of a prolonged period of immobility includes an integral recovery that consists of reprogramming and adjustments that need to be "reincorporated" into the body image, into the self-image. However, this recovery/ reincorporation does not automatically occur as a simple process, since it involves the whole system, the whole body, contemplated in its wider dimension. The recovery after each fracture, after each period of immobilization, requires more than the consolidation of the bone: it becomes necessary to learn unique "new ways", for the adaptation of both the central nervous system (CNS) and the person to the self-image and, consequently, his/her social and interactive functionality. In this "new way" some restrictions and guidelines are present, however, the way of incorporating them differs greatly from patient to patient, especially with regard to children.

In youths and adults, the recommendations seem to be accepted more consciously, with self-care and the gradual recovery of functionality being possible; however, in children and infants the issue changes, as they need the effective participation of their parents. This family participation occurs in different and unique ways: there are parents who seek to stimulate the children, encouraging their adaptation to these "new ways" for a "new functional image", and there are others who, due to fear of causing fractures, radically limit the attempts of their children in this rehabilitation process.

Physiotherapists use their hands as an epistemological principle, as a work instrument for the physical examination and the recognition of structural changes through palpation. However, they go further, as their work directly involves the hands as the clinical attribute, and sometimes physiotherapists use their bodies, among other resources, in contact with the patient, as a means of treatment. There is no way to approach individuals subjected to treatment without the touch, this being, more than a manual treatment technique, an important source of information (19).

With regard to touch, there are many variables to be considered, such as location (part of the body), pressure (light, firm), direction (proximal, distal), frequency and speed (slow, fast), rhythm (regular, irregular) and duration (length of time maintained) (12). 
The alternation, adaptation and adjustments of the touch during the handling should be directed by the needs of each individual and according to their responses. However, in general, they should convey confidence and trust, otherwise they amplify the apprehension regarding the physiotherapeutic intervention. We emphasize that we are referring to touch as a manual contact technique, different from what is known as the therapeutic touch (TT), which is an intervention performed by nursing professionals, developed by Dolores Kreiger and Dora Kunz, and, according to Janet Quinn, cited by Umphred (21), is based on a set of assumptions based on physics and bioelectromagnetic field principles.

As a way to extend and enhance the knowledge for the professional practice of physiotherapy in relation to tactile stimuli and preventive actions, we expanded our experiences beyond the possibilities that the Physiotherapy Program CROI/IFF was able to offer. As participants of a public health policy, our movements were directed toward approaching the patients during and after the consultations performed in the physiotherapy sector, as well as assisting the parents with specific guidelines suitable to be carried out in their homes, considering the socioeconomic conditions of each. The issue involved both the interaction with the patients, their parents and family members, as well as their adherence to our guidelines, aiming to minimize the fear of the possibility of fractures at the beginning of the motor development or in the recovery period of their children.

The early incentive to perform active movements in a safe environment, even after a fracture, led to important repercussions beyond the reduction of joint contractures, as we noticed improvements in muscle tone and that the handling became well accepted by babies and children. We realized that the specific manipulations allowed changes of position in the crib or bed, providing well-being, better accommodation and a type of movement that became desired by the patients. Our performances began to have an even greater significance than purely therapeutic actions, in that they contributed to better motor control, greater bone strength and muscle strengthening and the reduction of secondary complications, such as edema, poor blood circulation, constipation and atypical motor functions.

The sensory experience of the handling provided became clear due to its relevance in the approach and motivation for the performance of functional activities. The tactile stimuli allowed these experiences to become decisive factors for the treatment, with the improvement of proprioceptive sensitivity, balance, conscientization and organization of the sensorimotor functions, such as playing, dressing and painting, among others, that occur in the environment and that enable increasingly complex movement.

With the predominance of the tendency toward immobility imposed by this disease, the handling led to an approach that provided more comfort related to the postural changes and frequent transfers, facilitating the integration of body awareness related to the action of the movements $(22,23)$ and of the responses to tactile, kinesthetic and vestibular stimuli. They also helped in the functional capacity of integration with the environment, resulting in increased autonomy in movements, also constituting a preventive clinical attitude.

The planning of strategies as a way to recover the "tactile acceptance" necessary for the physiotherapy interventions in patients with IO, especially babies and children, or after the occurrence of fractures and immobilization time, was decisive in order to create new alternatives for actions to develop a clinical practice that promotes in them the confidence necessary to perform the postural changes and to assist in coordination of the fundamental movements to carry out daily activities such as bathing, feeding and walking, among others.

During our clinical practice, we met with mothers of children with the most severe forms of the disease, who arrived with their children lying on cushions or "egg box" pillows, supported by rolls made with blankets or bath towels, in order to avoid friction as much as possible, or even contact with their bodies, due to their worry about preventing an accident or fracture. They spoke about their difficulties of finding the best position for breastfeeding, of putting them down to sleep and of performing hygiene care, such as bathing and changing diapers. They tried to move them as little as possible, did not sit them in their laps, did not allow siblings to approach them, restricted their handling to a few family members who helped in the care, and only took them from the bed for care activities, believing that they could protect them with these measures. There were cases of suspected abuse and some were referred to the protection council of their region. One mother even lost custody of the child until the diagnosis of IO was confirmed, causing 
embarrassment, distress and unfortunate emotional repercussions for the entire family.

All this information was essential to perceive the amount of care required by these patients and the importance of the involvement and clarification of their family members. Regarding the guidelines offered to parents, one of the biggest difficulties was related to the adherence to attitudes that promote the appropriate postural changes required for the achievement of the motor milestones of the children. We realized that they understood what needed to be done, however, the main question was: how do I perform them without risk? The insecurity of the mothers was present at all times, throughout the care, and the possibility to stimulate the mobility seemed threatening to them.

In the children, after a period of immobilization due to fractures, this fear became even greater, both for them and for their parents. Therefore, it was important to present them with the means and design appropriate guidelines, minimizing the immobilizing consequences of the fear, which would enabled them to encourage the motor development of their children.

In this sense, water played a key role, not only due to its physical properties, but also due to it promoting sensorimotor integration and enabling the children to return to moving safely and in playful way, without them realizing that they were performing the activities necessary to assist their recovery.

Based on prior knowledge about the benefits of water as a therapeutic resource in many other treatments, and in order to promote specific gains that can be transferred to the ground, we concluded that to be viable parents should offer their children more frequent contact with water. We suggested that they could provide their children with longer periods in the bath, performed in a bathtub filled to the maximum level according to the size of each child, ensuring that the water temperature is maintained as is usual and well accepted, with the children generally enjoying these moments of contact with water.

It was asked that, during this prolonged bath, in addition to touching their children with the intention of cleaning them, they firmly touch the whole body with the hands for the longest time possible. The use of sponges with different textures and observation of the motor behavior of their children were also suggested. As expected by us, these parents reported that the children moved better during the bath and, even more, that they observed the performance of certain movements that they did not do out of the water. They emphasized how the children felt resourceful, without apparent fear and freer to play with their toys and interact.

As these children were developing and their parents becoming confident regarding their mobility, we proposed immersion in small plastic pools, for hot days and in a safe environment, with a size favoring the performance of small movements to the front and side of the body to pick up the toys. This would also allow the execution of some postural transitions, such as moving from sitting to kneeling to all fours, as well as remaining in the sitting position. With these constant activities in the water, the patients better perceived their motor possibilities and their parents were surprised by their performance. Thus, the delay in the motor development was minimized in many cases.

The majority of the children who suffered fractures also benefited from the physical effects of the water, especially those who had already started walking. After removal of the plaster cast, many of them refused to walk due to fear of falling down or insecurity caused by muscle weakness as a result of the immobilization period: they maintained the standing position, however, transferring the weight of the body forward and with support of the arms with some type of structure to aid the balance, without performing the steps. Sweating, a clinical feature of IO, often increased with every attempt to let go of the support, a fact that made the children even more apprehensive and sometimes triggered crying and reluctance to reinitiate walking.

From early on, many children with IO suffer fractures and develop body defense mechanisms in order to avoid pain or movement for fear of recurrences. The experience makes them realize that movements are synonymous with risk, and increases the fear of the parents regarding the need for permanent care when moving.

Despite the comprehension of the majority of the parents regarding the importance of mobility for the development of the children, this becomes an impasse when the children refusal to move about in the environment. There is no way to force them to perform certain functions without them presenting the spontaneous will to do so. For them to accept to move freely, their exposure to an environment that contains stimuli and makes them engage with these incentives is required. 
For example, faced with the descriptions of one family regarding the difficulty to reestablish the walking of their child after a fracture, since he did not want in any way to resume putting his feet on the ground and to recommence his routine, we requested information about the daily life of their son including the times of the day when he became more relaxed. In unison they responded that only during bathing did he relax a little more, risking some movements to play, however, remained sitting. Therefore, we planned daily bathing with the use of a large, resistant, plastic pail, compatible with the height and ability of the child, with sufficient water to cover approximately half of the trunk and supported by a non-slip mat to provide stability (Figure 1). With immersion, this patient benefited from movements in the standing position, performed squats, lateral waking safely inside the bucket and worked on muscle strength. In addition to the good acceptance by the child, the use of this device promoted increased interaction with the family, helping to reveal the natural abilities and efficiency of movement, with the patient freely reinitiating walking in other places, which resulted in loss of the fear of playing in diverse environments, such as playgrounds and party houses, leading to him to interact with other children.

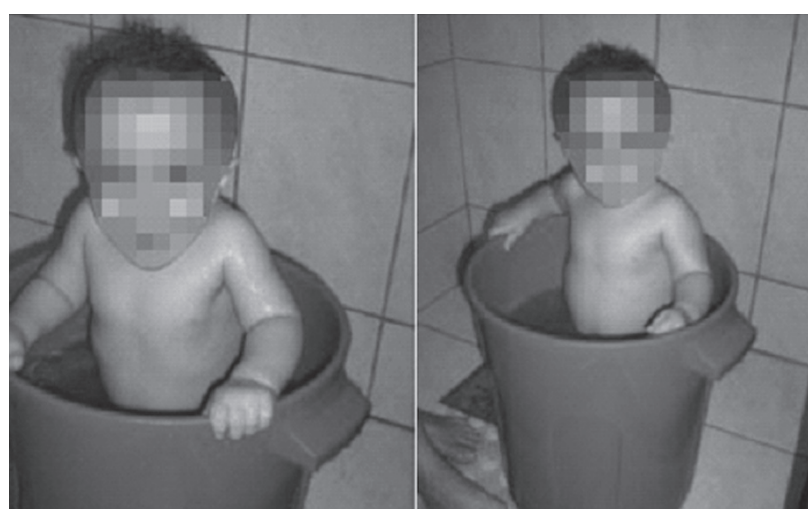

Figure 1 - Adapted devices

In another similar case we designed, together with the family, a larger swimming pool for use in the outdoor area of the house, such as the garden or garage. For this, water pipes and connections with the material polyvinyl chloride (PVC), recognized as hard and resistant, were adapted into a structure of connected parallel bars arranged securely and attached to the plastic pool. The child began to perform lateral and forward walking; supporting herself on the bars, she achieved free mobility for activities and games which simultaneously fulfilled her physiotherapeutic activities without fear. After a few days of activity, walking was achieved out of the water without suffering. The water provided the patient with confidence and represented a safe way for the parents to encourage their daughter to walk (Figure 2).
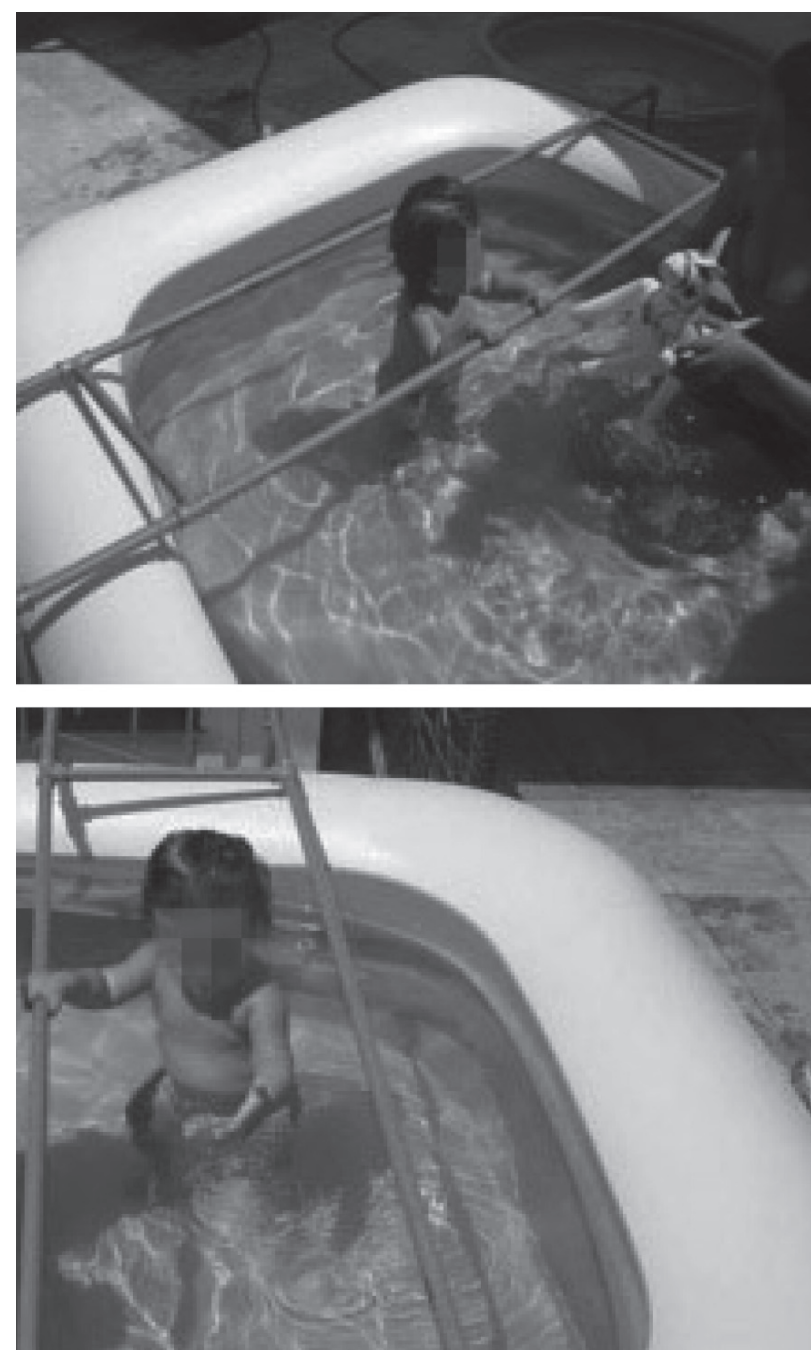

Figure 2 - Walking in water

We highlight that the success of this experience led us to the idea of encouraging the practice of swimming for children and adolescents who expressed willingness to practice some type of sport, however, were faced with the barriers imposed by the majority of them, such as high impact, the collision of bodies and possible falls. The guidance for this practice was only indicated for those with motor qualities and also 
for those needing to work the respiratory muscles, due to presenting retraction of the inspiration accessory muscles, pectus excavatum or scoliosis. With swimming, these patients can use the properties of water in all its aspects, as the absence of gravity provides greater freedom of movement and the possibility to work on large groups of muscles without impact (12). Added to the physical and respiratory issues mentioned are related benefit, such as sociability and improved self-esteem.

Another problem which we faced was that of the children who make early use of a wheelchair and often develop severe scoliosis, progressing to respiratory complications. The first step is to perform a comprehensive evaluation of the restricted motor possibilities. In general, children thus affected have great difficulty performing postural transitions, such as the transfer to a wheelchair or elsewhere, walking with support equipment or even dragging themselves along the floor. With the performance of the systematic assessment, we conclude that the guidelines should primarily focus on these difficulties and that the adherence of the parents or guardians is dependent on the comprehension that the movement depends on the change in position or posture, involving, as highlighted by Hamill and Knutzen (24), in addition to the obvious energy expenditure, control and the production of force.

The case of one adolescent, in our sample universe, exemplifies this issue well. She came from another state to start treatment at CROI/IFF; she could not even lie down and would sleep practically sitting, remaining in this position with the support of pillows or cushions. She presented serious deformity of the chest, severe scoliosis and moderate repertory difficulty with exertion. She was transferred from the bed to the wheelchair only when taken to the bathroom or when she had to leave the house. Her social life was limited to the family and a few neighbors; she no longer attended school and had virtually no friends her age. We started with the training of incomplete postural changes and focused on the transition from the sitting position to lying down. The first effort was to help her lose the fear of lying down, as this caused her great discomfort, including difficulty breathing. Little by little, we reduced the height of the pillows to arrive at a normal height. Then we trained the sitting position without support, which was greatly celebrated by the patient because she had no longer believed it would be possible (Figure 3). Finally, we proceeded to transfers to the wheelchair. The family members were involved in encouraging mobility, despite initial resistance, because in addition to the known fear of fractures ("countless" according to their statements), due to the debilities of the adolescent, they had already given up, after long periods of insistence, on the performance of movements, which had further contributed to her motor weakness and deformities. The family eventually moved to Rio de Janeiro and the patient returned to school, made new friends and went on to have an active social life. The wheelchair became an acceptable means of mobility, with new possibilities and conquests.

Babies, in turn, are patients who raise concerns about the efficiency of the clinical practices because they are in full psychomotor development. These concerns are magnified when we face the exacerbated fear of parents related to allowing the mobility of the infants for fear of causing fractures. Despite this fear permeating the universe of all those who care for these babies, including health professionals, knowledge of the need to stimulate motor gains should be emphasized. It becomes necessary to guide parents in order to prevent the restriction of mobility entailing problems and delayed motor development.

In one of the cases treated, which illustrates this situation, the parents could not position the child with the body organization necessary for good postural alignment. We advised them regarding the positioning of the hands to hold the child and stabilize his positions. Thus, our aim was to provide new perspectives to see the environment and interact with it, and with the people around. Gradually, the parents felt able to collaborate with the suggested positioning and with the daily activities proposed for the baby. Comprehending the importance of positioning him correctly so that he could observe and explore the environment from other angles or levels also provided new possibilities of proximity and care (Figure 4).

The involvement of the children during the physiotherapeutic treatment makes a difference, because this allows the motor responses to be expressed with higher quality and their attention to be maintained for longer. However, this does not simply occur with children with IO, as they face barriers imposed by the disease, such as pain and difficulty in moving due to bone deformities and muscle weakness, in addition to the fear already perceived and identified as a constant factor. 
Nevertheless, the initial approach to these children should be directed toward interaction, considering the first stages of sensorimotor intelligence and the later stages of cognitive development, based, according to Fonseca (18), on what Piaget called internalization, as well as on the active imagination of intentional motor acts. For Fonseca, both are projected in the movements with objects, as it is through them that young children are able to acquire the ability to "anticipate and make realistic predictions of changes in the environment" (18, p. 94).

In accordance with such assertions, we always propose a functionally relevant approach. We suggest the manipulation of objects and toys, starting with the most simple and light, gradually introducing the more complex and heavy, in order to retain the child's attention and increase the length of the handling (Figure 5).
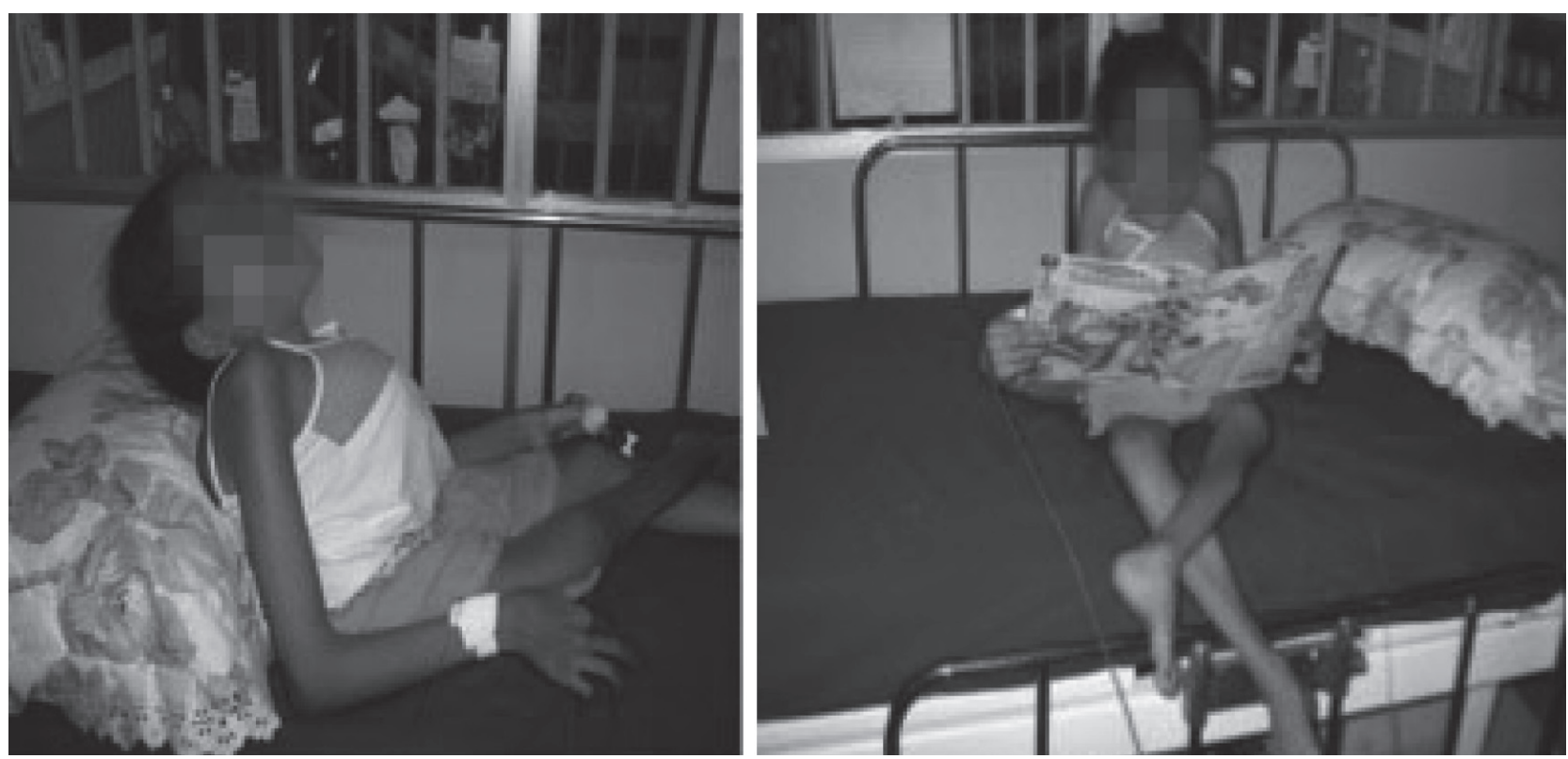

Figure 3 - Sitting posture without support

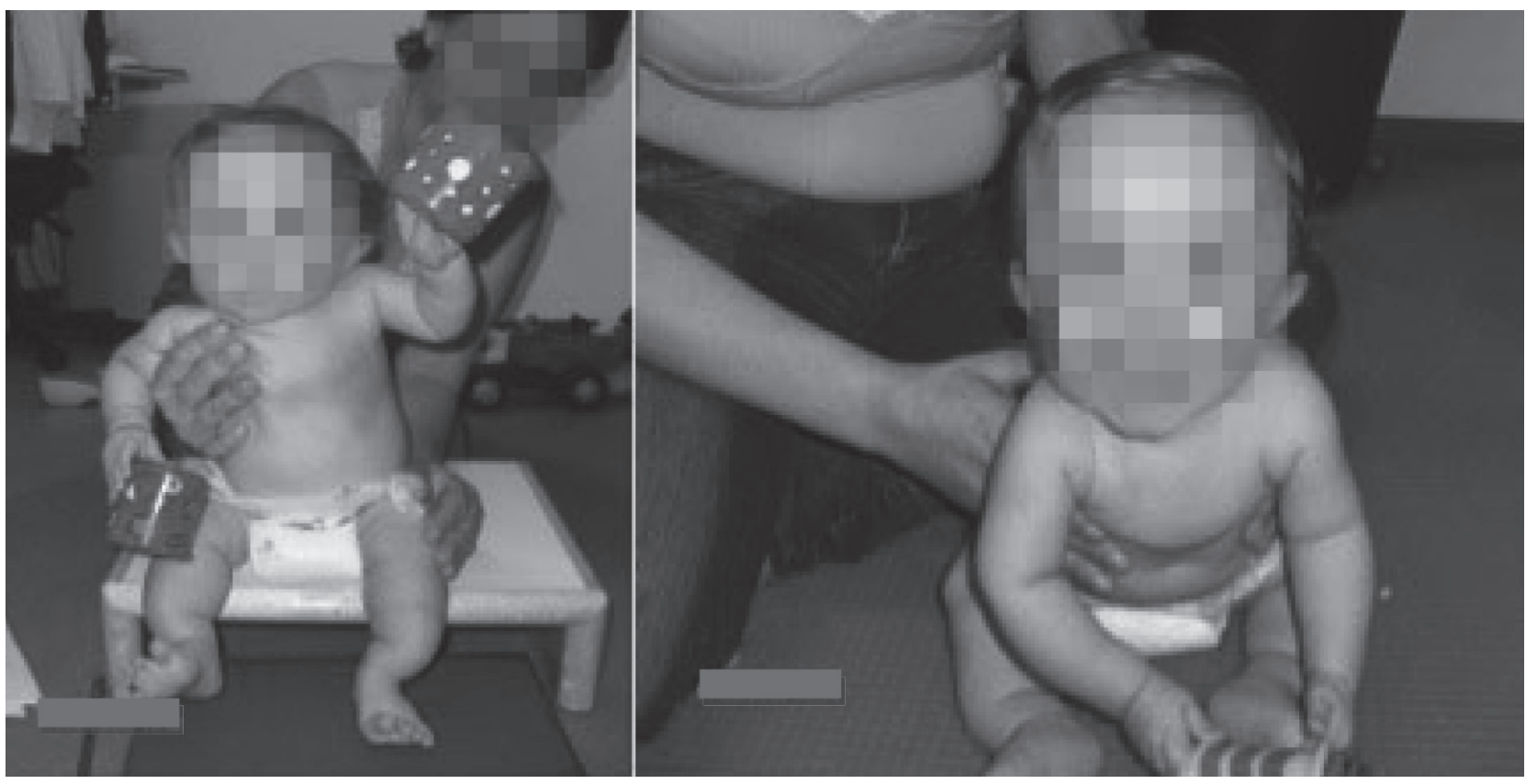

Figure 4 - Correct positioning 


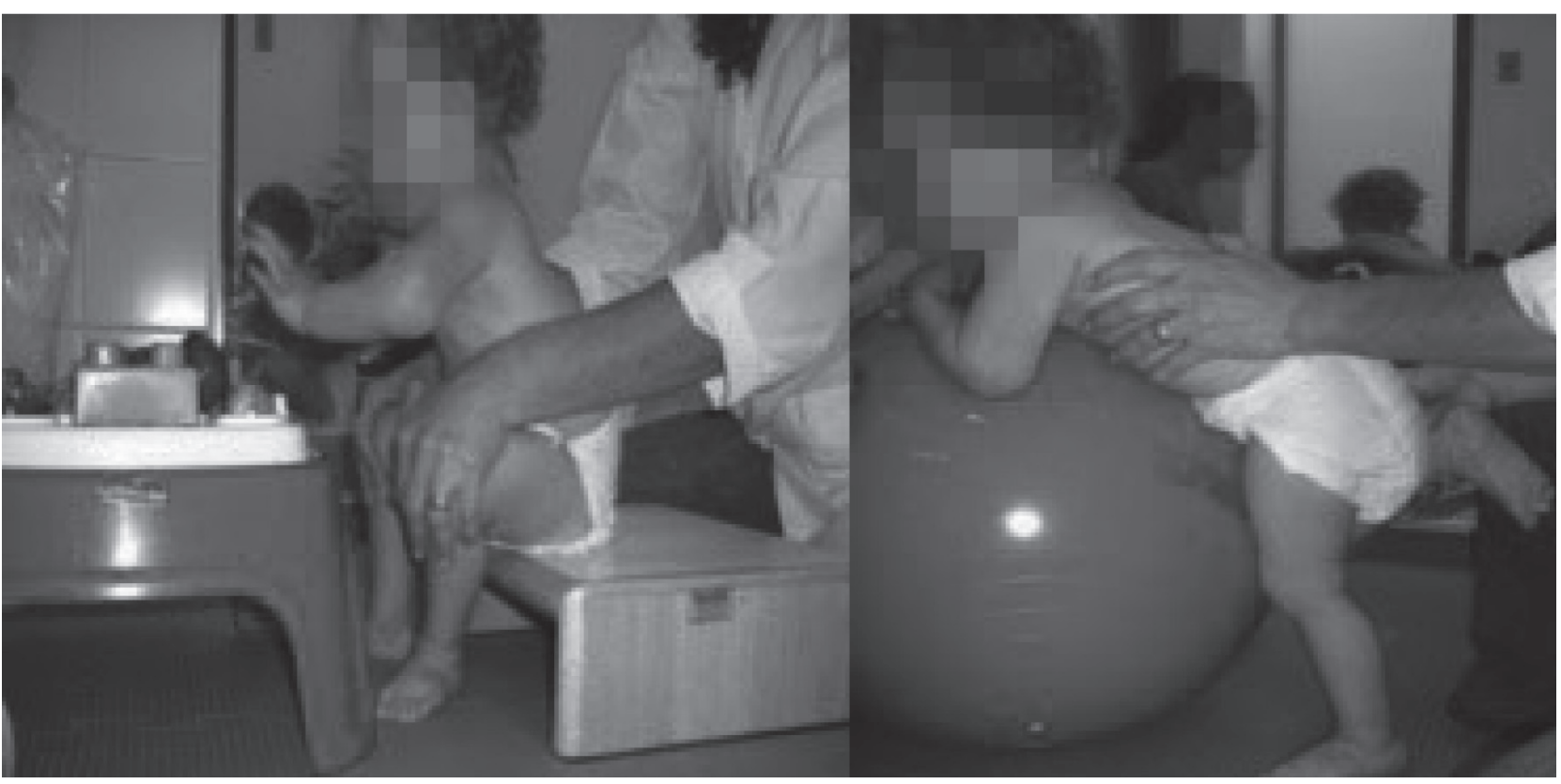

Figure 5 - Manipulation of objects and toys

In these moments we are attentive to whether they perform activities with the best possible biomechanical alignment, while simultaneously working the muscle groups required to maintain good posture and stimulate functional independence. Thus, convinced that, as with motor control, motor learning arises from a complex process of perception, cognition and action (25), we aim to provide all the stimuli, seeking these aspects and also that the activities and positions have enough time to occur, through the processes involved in the interaction of the body systems and the environment.

In summary, the analysis of our experience allows us to state that the motor act in patients with IO is related to diverse factors. It is evident that to understand the aspects involved in the physiotherapy offered at CROI/IFF, we must take into consideration the dynamics surrounding the complex relationship between the individuals and their environment, also paying attention to their particular experiences.

\section{Conclusion}

The experience of CROI/IFF demonstrated that physiotherapy work is an instrument of fundamental importance for improving the motor skills of individuals with IO. However, to contextualize their universe and that of their family members is essential to perceive the dimension of the aspects involved in the treatment.

Given the experience acquired and the results achieved we suggest, with respect to clinical physiotherapy as a treatment complementary to the use of PD, that the care directed toward patients with IO should be expanded, in order to show the tactile-kinesthetic stimuli and preventive actions as therapeutic attributes of recognized value, both in terms of their efficiency and as important sources of information in the treatment. We therefore emphasize that the physiotherapeutic approach involves not only the neurofunctional components, but also covers the multiple dimensions of the patients and their family members. From this perspective, the work should be developed in the direction of engagement with a learning process that promotes changes in the sensorimotor perception, as a means of social integration, through the potential of patients and the recognition of their competence and pleasure in the exercise of their own abilities.

Furthermore, the experiences described here also refer to the therapeutic tools that support the quality of information sent to the CNS, in order to encourage better body organization. The therapeutic resources used favored effective responses to the clinical practice, allowing a better dimensioning of the importance of the tactile stimulation and of the motivation of mobility as main aspects in the physiotherapeutic care to patients with IO. 


\section{References}

1. Engelbert RHH, Uiterwaal CS, Grever WJ, van der Net JJ, Pruijs HE, Helders PJ. Osteogenesis imperfecta in childhood: impairment and disability. A prospective study with 4-year follow-up. Arch Phys Med Rehabil. 2004;85(5):772-8.

2. Sillence DO, Senn A, Danks DM. Genetic heterogeneity in osteogenesis imperfecta. J Med Genet. 1979; 16(2):101-16.

3. Glorieux FH, Rauch F, Plotkin H, Ward L, Travers R, Roughley P, et al. Type V osteogenesis imperfecta: a new form of brittle bone disease. J Bone Miner Res. 2000;15(9):1650-8.

4. Glorieux FH, Ward LM, Rauch F, Lalic L, Roughley PJ, Travers R. Osteogenesis imperfecta type VI: a form of brittle bone disease with a mineralisation defect. J Bone Miner Res. 2002;17(1):30-8.

5. Ward LM, Rauch F, Travers R, Chabot G, Azouz EM, Lalic L, et al. Osteogenesis imperfecta type VII: an autosomal recessive form of brittle bone disease. Bone. 2002;31(1):12-8.

6. Cabral WA, Chang W, Barnes AM, Weis M, Scott MA, Leikin S, et al. Prolyl 3-hydroxylase 1 deficiency causes a recessive metabolic bone disorder resembling lethal/severe osteogenesis imperfecta. Nat Genet. 2007; 39(3):359-65.

7. van Dijk FS, Byers PH, Dalgleish R, Malfait F, Maugeri A, Rohrbach M, et al. EMQN best practice guidelines for the laboratory diagnosis of osteogenesis imperfecta. Eur J Hum Genet. 2012;20(1):11-9.

8. Plotkin H. Two questions about osteogenesis imperfecta. J Pediatr Orthop. 2006;26(1):148-9.

9. Brasil. Ministério da Saúde. Portaria n. 2305, de 19 de dezembro de 2001. Aprova o Protocolo de Indicação de Tratamento Clínico da osteogenesis imperfecta com pamidronato dissódico no âmbito do Sistema Único de Saúde - SUS. Diário Oficial da União. 20 dez 2001.

10. Effegen SK. Fisioterapia pediátrica. atendendo às necessidades das crianças. Rio de Janeiro: Guanabara Koogan; 2007.

11. Shepherd RB. Fisioterapia em pediatria. 3. ed. São Paulo: Santos; 1995.
12. Moura EW, Lima E, Borges D, Silva PAC. Fisioterapia: aspectos clínicos e práticos da reabilitação. São Paulo: Artes Médicas; 2010.

13. Organização Mundial de Saúde; Organização Panamericana de Saúde. CIF: Classificação Internacional de Funcionalidade, Incapacidade e Saúde. São Paulo: Edusp; 2003.

14. Yin RK. Case study research. Los Angeles: Sage; 2009.

15. Cardoso CF. Narrativa, sentido, história. Campinas: Papirus; 1997.

16. Cohen H. Neuroscience for rehabilitation. Philadelphia: Lippincott; 1999

17. Lundy-Ekman L. Neurociência: fundamentos para a reabilitação. Rio de Janeiro: Guanabara Koogan; 2000.

18. Fonseca V. Desenvolvimento psicomotor e aprendizagem. Porto Alegre. Artemed; 2008.

19. Turvey MT. Dynamic touch. Am Psychol. 1996;51(11): 1134-52.

20. Fernandes AC, Ramos ACR, Casalis MEP, Hebert SK. aacd: medicina e reabilitação: princípios e práticas. São Paulo: Artes Médicas; 2007.

21. Umphred DA. Reabilitação neurológica. 4. ed. Barueri: Manole; 2004.

22. Berthier NE, Keen R. Development of reaching in infancy. Exp Brain Res. 2006;169(4):507-18.

23. Thelen E. Motor development: a new synthesis. Am Psychol. 1995;50(2):79-95.

24. Hamill J, Knutzen KM. Bases biomecânicas do movimento humano. São Paulo: Manole; 1999.

25. Shumway-Cook A, Woollacott MH. Controle motor: teorias e aplicações práticas. São Paulo: Manole; 2003.

Received: 06/11/2012

Recebido: 11/06/2012

Approved: 03/09/2015 Aprovado: 09/03/2015 
